\title{
Increase in Total Joint Arthroplasty Projected from 2014 to 2046 in Australia: A Conservative Local Model With International Implications
}

\author{
Maria C. S. Inacio PhD, Stephen E. Graves MBBS, DPhil, Nicole L. Pratt PhD, \\ Elizabeth E. Roughead PhD, Szilard Nemes PhD
}

Received: 21 October 2016/Accepted: 28 April 2017/Published online: 9 May 2017

(C) The Association of Bone and Joint Surgeons (B) 2017

\begin{abstract}
Background The incidence of joint arthroplasty is increasing worldwide. International estimates of future demand for joint arthroplasty have used models that propose either an exponential future increase, despite obvious
\end{abstract}

The institution of one or more of the authors (MCSI, NLP, EER) has received, during the study period, funding from the Australian Government National Health and Medical Research Council (NHMRC) Centre of Research Excellence in Post-Marketing Surveillance of Medicines and Medical Devices grant (GNT1040938; GNT1035889 [NLP]; GNT1110139 [EER]).

All ICMJE Conflict of Interest Forms for authors and Clinical Orthopaedics and Related Research ${ }^{\circledR}$ editors and board members are on file with the publication and can be viewed on request.

Clinical Orthopaedics and Related Research ${ }^{\circledR}$ neither advocates nor endorses the use of any treatment, drug, or device. Readers are encouraged to always seek additional information, including FDAapproval status, of any drug or device prior to clinical use.

Each author certifies that his or her institution approved or waived approval for the human protocol for this investigation and that all investigations were conducted in conformity with ethical principles of research

This work was performed at the University of South Australia (Adelaide, Australia) and Swedish Hip Arthroplasty Register (Gothenburg, Sweden).

M. C. S. Inacio $(\bowtie)$, N. L. Pratt, E. E. Roughead

School of Pharmacy and Medical Sciences, Medicine and Device Surveillance Centre of Research Excellence, Sansom Institute, University of South Australia, GPO Box 2471, Adelaide 5001, SA, Australia

e-mail: maria.inacio@unisa.edu.au

\section{S. E. Graves}

Australian Orthopaedic Association National Total Joint Replacement Registry, South Australian Health and Medical Research Institute, Adelaide, Australia

S. Nemes

Swedish Hip Arthroplasty Register, Gothenburg, Sweden system constraints, or static increases, which do not account for past trends. Country-specific projection estimates that address limitations of past projections are necessary. In Australia, a high-income country with the 7th highest incidence of TKA and 15th highest incidence of THA of the Organization for Economic Cooperation and Development (OECD) countries, the volume of TKAs and THAs increased 198\% between 1994 and 2014.

Questions/purpose To determine the projected incidence and volume of primary TKAs and THAs from 2014 to 2046 in the Australian population older than 40 years.

Methods Australian State and Territory Health Department data were used to identify TKAs and THAs performed between 1994 and 1995 and 2013 and 2014. The Australian Bureau of Statistics was the source of the population estimates for the same periods and populationprojected estimates until 2046. The incidence rate (IR), 95\% CI, and prediction interval (PI) of TKAs and THAs per 100,000 Australian citizens older than 40 years were calculated. Future IRs were estimated using a logistic model, and volume was calculated from projected IR and population. The logistic growth model assumes the existence of an upper limit of the TKA and THA incidences and a growth rate directly related to this incidence. At the beginning, when the observed incidence is much lower than the asymptote, the increase is exponential, but it decreases as it approaches the upper limit.

Results A $66 \%$ increase in the IR of primary THAs between 2013 and 2046 is projected for Australia (2013: IR $=307$ per 100,000 , [95\% CI, 262-329 per 100,000] compared with 2046: IR= 510 per 100,000 , [95\% PI, 98-567 per 100,000]), which translates to a $219 \%$ increase in the volume during this period. For TKAs the IR is expected to increase by $26 \%$ by 2046 (IR $=575$ per 100,$000 ; 95 \%$ PI, 402-717 per 100,000) compared with 2013 (IR $=437$ per 
$100,000 ; 95 \%$ CI, $397-479$ per 100,000$)$ and the volume to increase by $142 \%$.

Conclusion A large increase in the volume of arthroplasties is expected using a conservative projection model that accounts for past surgical trends and future population changes in Australia. These findings have international implications, as they show that using country- specific, conservative projection approaches, a substantial increase in the number of these procedures is expected. This increase in joint arthroplasty volume will require appropriate workforce planning, resource allocation, and budget planning so that demand can be met.

Level of Evidence Level II, economic and decision analysis.

\section{Introduction}

Although the incidence rate (IR) of joint arthroplasty varies by country [17, 23, 24, 26], a consistent historical increase in the incidence of joint arthroplasty has been reported worldwide [7-12, 20, 23-26]. Many reasons have been reported or postulated to explain this increase in joint arthroplasties, including aging of the general population [17], the increase in obesity worldwide [27], an increase in osteoarthritis prevalence [17], benefits in patients ' quality of life and function, supplier-induced demands, expansion of surgical indications, and patient-driven behavior [16].

International future projections of joint arthroplasty exist, and while they differ in magnitude, all report increases in overall volume of TKAs and THAs with time $[9,10,20,21,25]$. Projections can be made using data on past numbers of joint arthroplasties, combined with appropriate modeling based on maximum prevalence and assumptions regarding the future population. Modeling techniques, such as Poisson regression, commonly used in previous international studies [10, 12, 25], allow for an ever-increasing rate of procedures and do not account for maximum prevalence. As a result, these models are likely to produce overestimates of the future burden of procedures. This is because the method fails to cap projections when the maximum prevalence is reached. Models that include the maximum incidence of procedures in the calculation of future projections yield more-conservative projections while not assuming a static rate, and these have been proposed as an alternative [20, 21].

Furthermore, while there has been an increase in the crude IR and therefore volume of joint arthroplasties $[5,28]$, there are no published studies, to our knowledge, evaluating the projections of future demand for these procedures in Australia. Australia is a high-income country where 95,000 joint arthroplasties were performed in 2014 [6], and the lifetime risks of a citizen with osteoarthritis needing a TKA or THA in 2013 were $15 \%$ to $21 \%$ and $11 \%$ to $13 \%$ respectively $[1,2]$. The volume and crude IR of these procedures in the overall population has gradually increased [28], with a recent estimate of a $198 \%$ increase in the volume of hip and knee arthroplasties between 1994 and 2014 [6]. Like other western countries, joint arthroplasty is one of the elective surgical procedures with the highest burden in Australia, and a high IR for these procedures, especially TKAs, already exists [23, 24]. In addition, like in other western countries, Australia has experienced a substantial increase in the many factors that contribute to the greater incidence of joint surgery. Furthermore, as in other smaller countries, estimations of future demand have been based on the expectation of projections made for countries like the US, which used unrealistic projection models 12,13$]$. Therefore, adequate estimations of future need are crucial in guiding health policy for preparing and planning future healthcare needs for providers, resources, and budgets. We propose that countries should estimate their own future demand based on suitable models for their patient population and healthcare system.

The purpose of this study was to forecast the yearly IR of primary TKAs and THAs in Australia between 2014 and 2046 and determine the future demand for these procedure's.

\section{Methods}

A population-based epidemiologic study in Australia was conducted. In September 2015 the population of Australia was 23,860,100 [3]. Between 1994 and 2013, Australia's population increased by $30 \%$ (Table 1 ).

The volumes of primary TKAs and THAs from 1994 to 1995 to 2013 to 2014 were identified using the Australian Classification of Health Intervention codes in the Australian State and Territory Health Department databases. TKAs were identified using the codes 49518, 49519, 49521*, 49524* and THAs using 49318, 49319, and 90607* [5]. The Australian Bureau of Statistics data (Series B) were used to identify the historical population estimates for the same years and projected population estimates until 2046 for denominator information [3].

The IR and 95\% CI of TKAs and THAs per 100,000 Australian citizens older than 40 years were calculated. The incidence in the population 40 years or older was chosen because the number of patients with joint arthroplasties younger than 40 years is minimal $(0.3 \%$ of TKAs and $1.6 \%$ of THAs from 1999 to 2014) [4].

The total numbers of procedures performed in Australia between 1994 and 2013 were 400,076 THAs and 521,910 TKAs. Between 1994 and 2013 an $82 \%$ increase in the IR of THAs, at a rate per 100,000 of 1036 operations per year 
Table 1. Primary THAs and TKAs in the Australian population and annual crude incidence rate per 100,000 citizens 40 years or older, $1994-$ 2014

\begin{tabular}{|c|c|c|c|c|c|c|c|}
\hline Year & $\begin{array}{l}\text { Total population } \\
\text { (number) }\end{array}$ & $\begin{array}{l}\text { Population } \geq 40 \text { years } \\
\text { (number) }\end{array}$ & $\begin{array}{l}\text { Proportion } \geq 40 \\
\text { years }(\%)\end{array}$ & $\begin{array}{l}\text { THAs } \\
\text { (number) }\end{array}$ & $\begin{array}{l}\text { IR THA } \geq 40 \text { years } \\
(95 \% \mathrm{CI})\end{array}$ & $\begin{array}{l}\text { TKAs } \\
\text { (number) }\end{array}$ & $\begin{array}{l}\text { IR TKA } \geq 40 \text { years } \\
(95 \% \mathrm{CI})\end{array}$ \\
\hline 1994-1995 & $17,843,268$ & $7,051,514$ & 40 & 11,421 & $162(137-187)$ & 12,030 & $171(146-197)$ \\
\hline 1995-1996 & $18,071,758$ & $7,221,273$ & 40 & 12,012 & $166(142-193)$ & 13,090 & $181(156-209)$ \\
\hline 1996-1997 & $18,310,714$ & $7,404,891$ & 40 & 12,549 & $169(145-196)$ & 13,792 & $186(161-214)$ \\
\hline 1997-1998 & $18,524,155$ & $7,583,660$ & 41 & 13,545 & $179(153-206)$ & 15,599 & $206(178-235)$ \\
\hline 1998-1999 & $18,730,359$ & $7,768,874$ & 41 & 13,848 & $178(153-206)$ & 17,097 & $220(192-251)$ \\
\hline 1999-2000 & $18,966,788$ & $7,950,750$ & 42 & 14,193 & 179 (153-206) & 15,597 & $196(170-225)$ \\
\hline $2000-2001$ & $19,225,331$ & $8,215,397$ & 43 & 15,373 & $187(162-215)$ & 17,097 & $208(181-238)$ \\
\hline 2001-2002 & $19,485,278$ & $8,433,216$ & 43 & 17,378 & $206(179-236)$ & 20,296 & $241(211-272)$ \\
\hline $2002-2003$ & $19,662,781$ & $8,606,134$ & 44 & 18,534 & $215(188-245)$ & 21,540 & $250(220-282)$ \\
\hline 2003-2004 & $19,872,646$ & $8,819,746$ & 44 & 19,380 & $220(191-249)$ & 23,132 & $262(232-295)$ \\
\hline 2004-2005 & $20,127,363$ & $8,985,606$ & 45 & 20,683 & $230(202-261)$ & 25,428 & $283(250-316)$ \\
\hline 2005-2006 & $20,394,791$ & $9,166,943$ & 45 & 21,050 & $230(201-260)$ & 27,049 & $295(263-330)$ \\
\hline 2006-2007 & $20,697,880$ & $9,341,782$ & 45 & 21,971 & $235(206-266)$ & 28,835 & $309(275-344)$ \\
\hline 2007-2008 & $21,015,042$ & $9,527,661$ & 45 & 23,268 & $244(215-276)$ & 31,464 & $330(296-367)$ \\
\hline 2008-2009 & $21,373,998$ & $9,714,982$ & 45 & 23,999 & 247 (218-279) & 33,189 & $342(306-379)$ \\
\hline 2009-2010 & $21,778,845$ & $9.880,790$ & 45 & 25,736 & $260(230-293)$ & 35,702 & $361(325-400)$ \\
\hline 2010-2011 & $22,065,317$ & $10,070,806$ & 46 & 26,780 & $266(234-298)$ & 39,181 & $389(352-429)$ \\
\hline 2011-2012 & $22,323,933$ & $10,277,688$ & 46 & 27,733 & $270(238-303)$ & 41,552 & $404(366-445)$ \\
\hline 2012-2013 & $22,728,254$ & $10,500,056$ & 46 & 29,069 & $277(245-310)$ & 43,392 & $413(375-454)$ \\
\hline 2013-2014 & $23,125,868$ & $10,713,254$ & 46 & 31,554 & $295(262-329)$ & 46,848 & $437(397-479)$ \\
\hline
\end{tabular}

IR $=$ incidence rate.

(95\% CI, 978-1094), and a $156 \%$ increase in the IR of TKAs, at a rate per 100,000 of 1823 operations per year (95\% CI, 1658-1988) were observed.

The ability to predict future incidence is extremely useful to healthcare planning. This prediction can commence with different assumptions such as linear growth, exponential growth (eg, Poisson regression), or asymptotic growth models. These models have a common assumption, namely that the incidence number we observe today depends on the incidence numbers we observed yesterday, and yesterday's observation depends on the numbers for the day before. However, they assume different growth curves. The linear and the exponential models assume a constant increase, which might not be biologically plausible. The logistic model assumes that an upper limit exists for the incidences. This model assumes an S-shape curve. The model parameters have clear meanings. The differential equation of the logistic model is given by

$\frac{d y^{\prime}}{d t}=\beta y\left(1-\frac{y}{A}\right)$

where $y$ equals observed incidence, $A$ the asymptote that has units equal to incidence, and $\beta$ the growth rate with units equal to $t$ (years in our case). As one can see, if the observed incidence is far from the asymptote the growth is accentuated. However, as the observed incidence $y$ approaches the asymptote $A$ the growth slows down. The model parameters are estimated using its integrated form and routine optimization methods. This conservative projection model was tested by Nemes et al. [20, 21] for joint replacement prediction and was used in the current study. Prediction intervals (PIs) for projected IRs were calculated with the delta method [19]. Historical data were summarized as IR and associated $95 \% \mathrm{CI}$, while projections were presented with $95 \%$ PI. Projected volumes were calculated using the projected IRs and population estimates for the same periods. As a direct consequence of using a model based on a differential equation, the estimates of future incidences are not independent estimates but always depend on previous observations. Thus the errors associated with the predictions, which are used to calculate the PIs propagate, and direct comparison and inference of different times should be dealt with care. Unlike traditional CIs, PIs, because they incorporate the uncertainty of each previous estimate, become wider and wider and cannot directly be interpreted as in the classic case when two independent means are compared.

All analyses were conducted using R Version 3.2.3 (R Development Core Team, The R Foundation for Statistical Computing, Vienna, Austria). 
Fig. 1 The incidence rate (per $100,000)$ of primary THAs in Australian citizens 40 years and older is presented.

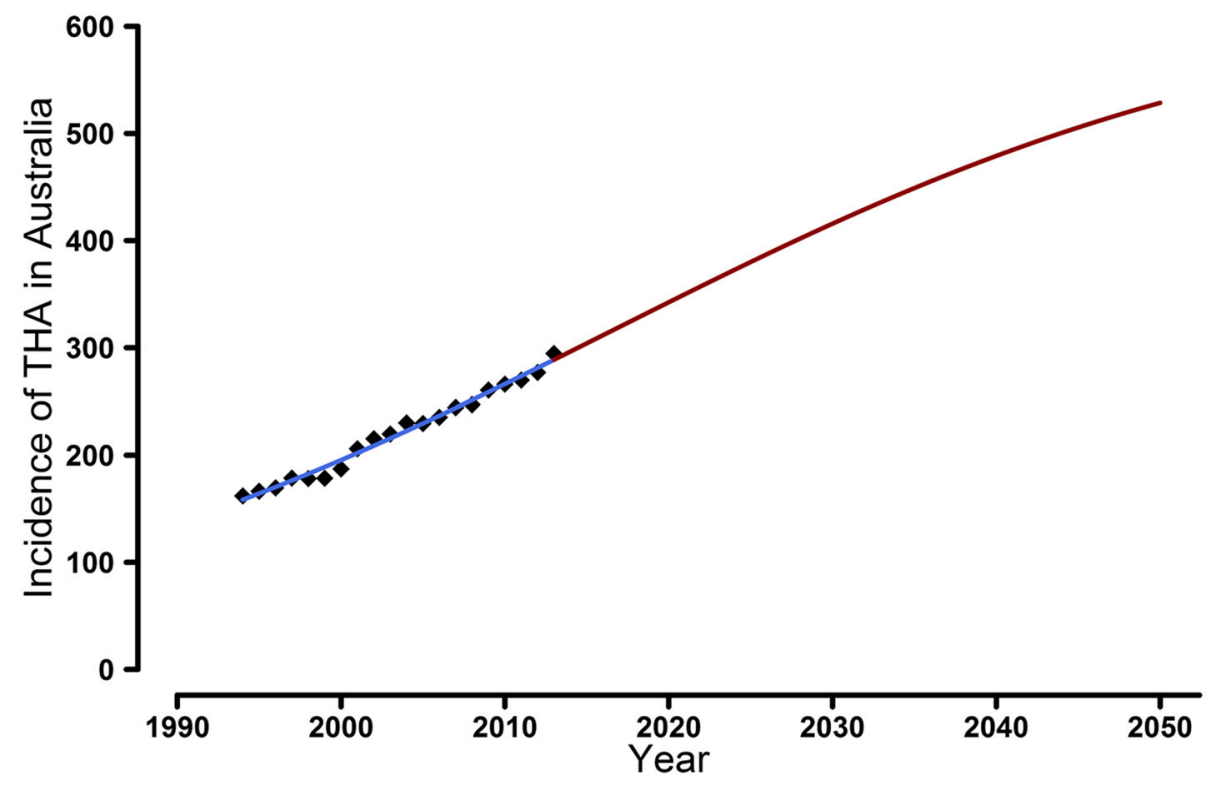

\section{Results}

We project a $73 \%$ increase in the IR of primary THAs between 2013 and 2046 for Australia (2013: IR = 295 per 100,000 , [95\% CI, 262-329 per 100,000] versus 2046: IR = 510 per 100,000 , [95\% PI, 98-567 per 100,000]) in patients 40 years and older (Fig. 1). The rate at which the IR is expected to increase is more than $2 \%$ per year until 2025 , after which it tapers off until it reaches $1 \%$ per year in 2046 (Table 2). This increase in IR equates to a $198 \%$ increase in the volume of procedures by 2046 (Table 3).

For TKAs the IR is expected to increase by $31 \%$ by $2046($ IR $=575$ per 100,$000 ; 95 \%$ PI, $402-717$ per 100,000$)$ compared with 2013 (IR = 437 per 100,000; 95\% CI, 397479 per 100,000) (Fig. 2), and translates to a $126 \%$ increase in the volume (Table 3). The rate at which the IR is expected to increase for TKAs will fall below $2 \%$ per year by $2019,1 \%$ per year by 2016 , and then gradually decrease until reaching a $0.1 \%$ increase per year in 2046 (Table 2).

\section{Discussion}

The ability to predict future demand of joint arthroplasty is extremely useful to healthcare planning as these surgeries have become some of the most-commonly performed major surgeries worldwide. However, often reported estimates of future demand of these surgeries have used unrealistic models [12, 13], which do not account for limitations in our healthcare system or they ignore past trends. In our study of the future demand in Australia for TKAs and THAs, we used conservative models to estimate our projections. This is important to surgeons and policymakers outside Australia because we propose projection models that are more realistic and account for countryspecific variables, which we recommend be pursued by other countries looking to prepare for future demand in joint surgery.

A substantial increase in the overall volume of joint arthroplasties is expected in Australia during the next three decades. Although the projected increases in IR of $73 \%$ for THAs and $31 \%$ for TKAs are not higher than during the past 20 years, the volumes of procedures in Australia are expected to increase by $198 \%$ for THAs and $126 \%$ for TKAs. These large increases in volumes are mostly attributable to the projected increase in the Australian population.

Our projections are inheritably limited by the assumptions underlying the modeling method that was used. Our analysis is based on past and recent incidences of joint arthroplasties and projected population growth, and therefore it does account for future changes in patient characteristics, physician capacity (such as surgical training and retirement), healthcare system, and political and population factors. However, we believe this is not a disqualifying limitation of our study as we assume these to be constant in the projected years, which we believe results in conservative projection estimates. We recognize that the future demands of joint arthroplasties in Australians also might increase if the proportion of patients who become obese should increase [27], if life expectancies increase, or if the prevalence of osteoarthritis continues to increase in the aging population [17]. We could not account for these factors in our analysis owing to data availability and modeling constraints. This limitation means our projections 
Table 2. Projected annual incidence rate per 100,000 citizens 40 years or older, 2014-2046

\begin{tabular}{|c|c|c|c|c|}
\hline Year & IR THA (95\% PI) & Annual growth rate $(\%)$ & IR TKA (95\% PI) & Annual growth rate $(\%)$ \\
\hline 2014 & $296(96-299)$ & - & $430(372-442)$ & - \\
\hline 2015 & $304(90-307)$ & 2.6 & $441(375-456)$ & 2.6 \\
\hline 2016 & $312(90-315)$ & 2.5 & $452(379-469)$ & 2.4 \\
\hline 2017 & $319(92-323)$ & 2.5 & $462(382-482)$ & 2.3 \\
\hline 2018 & $327(92-331)$ & 2.4 & $472(385-495)$ & 2.1 \\
\hline 2019 & $335(93-339)$ & 2.3 & $481(387-508)$ & 1.9 \\
\hline 2020 & $342(93-347)$ & 2.3 & $489(389-521)$ & 1.7 \\
\hline 2021 & $350(95-356)$ & 2.2 & $497(391-533)$ & 1.6 \\
\hline 2022 & $358(96-364)$ & 2.2 & $504(393-545)$ & 1.5 \\
\hline 2023 & $365(95-372)$ & 2.1 & $511(394-556)$ & 1.3 \\
\hline 2024 & $373(96-380)$ & 2.0 & $517(395-568)$ & 1.2 \\
\hline 2025 & $380(97-389)$ & 2.0 & $523(396-579)$ & 1.1 \\
\hline 2026 & $387(96-397)$ & 1.9 & $528(397-590)$ & 1.0 \\
\hline 2027 & $395(95-405)$ & 1.9 & $533(397-600)$ & 0.9 \\
\hline 2028 & $402(95-414)$ & 1.8 & $538(399-609)$ & 0.8 \\
\hline 2029 & $409(95-422)$ & 1.8 & $542(399-618)$ & 0.8 \\
\hline 2030 & $416(97-430)$ & 1.7 & $545(399-627)$ & 0.7 \\
\hline 2031 & $423(94-439)$ & 1.7 & $549(400-636)$ & 0.6 \\
\hline 2032 & 429 (99-447) & 1.6 & $552(400-644)$ & 0.6 \\
\hline 2033 & $436(95-456)$ & 1.5 & $555(400-651)$ & 0.5 \\
\hline 2034 & 443 (96-464) & 1.5 & $557(401-658)$ & 0.5 \\
\hline 2035 & 449 (98-473) & 1.4 & $560(402-665)$ & 0.4 \\
\hline 2036 & $455(98-481)$ & 1.4 & $562(401-671)$ & 0.4 \\
\hline 2037 & $461(95-490)$ & 1.3 & $564(402-677)$ & 0.3 \\
\hline 2038 & $467(98-498)$ & 1.3 & $566(401-683)$ & 0.3 \\
\hline 2039 & $473(96-507)$ & 1.3 & $567(401-689)$ & 0.3 \\
\hline 2040 & $479(98-515)$ & 1.2 & $569(402-693)$ & 0.3 \\
\hline 2041 & $485(98-524)$ & 1.2 & $570(402-698)$ & 0.2 \\
\hline 2042 & $490(100-532)$ & 1.1 & $571(401-703)$ & 0.2 \\
\hline 2043 & $495(93-541)$ & 1.1 & $572(402-707)$ & 0.2 \\
\hline 2044 & $501(95-550)$ & 1.0 & $573(403-711)$ & 0.2 \\
\hline 2045 & $506(97-558)$ & 1.0 & $574(402-715)$ & 0.2 \\
\hline 2046 & $510(98-567)$ & 1.0 & $575(402-717)$ & 0.1 \\
\hline
\end{tabular}

$\mathrm{IR}=$ incidence rate; $\mathrm{PI}=$ prediction interval.

Table 3. Yearly volume estimates for primary THAs and TKAs, 2016-2046

\begin{tabular}{lllll}
\hline Year & Total population & Population $\geq 40$ years & THAs, number (95\% PI ) & TKAs, number (95\% PI ) \\
\hline 2016 & $24,359,761$ & $11,330,173$ & $35,319(10,218-35,702)$ & $51,194(42,987-53,157)$ \\
2026 & $28,505,871$ & $13,694,299$ & $53,036(13,215-54,535)$ & $72,329(54,349-80,731)$ \\
2036 & $32,426,009$ & $16,257,033$ & $74,013(15,890-78,247)$ & $91,348(65,137-109,163)$ \\
2046 & $36,135,078$ & $18,431,259$ & $94,086(18,126-104,499)$ & $105,971(74,014-132,225)$ \\
\hline
\end{tabular}

$\mathrm{PI}=$ prediction interval.

are likely to be underestimated. Conversely, it is likely that our estimates are more liberal than would be the case if healthcare system restrictions are put in place. This also was not evaluated in our study. In addition, the population changes in Australia, which projections suggest will be the fastest-growing developed country in the world, could be affected by several political factors [18]. This cannot be accounted for in our analysis and it is difficult to determine 
Fig. 2 The incidence rate (per $100,000)$ of primary TKAs in Australian citizens 40 years and older is shown.

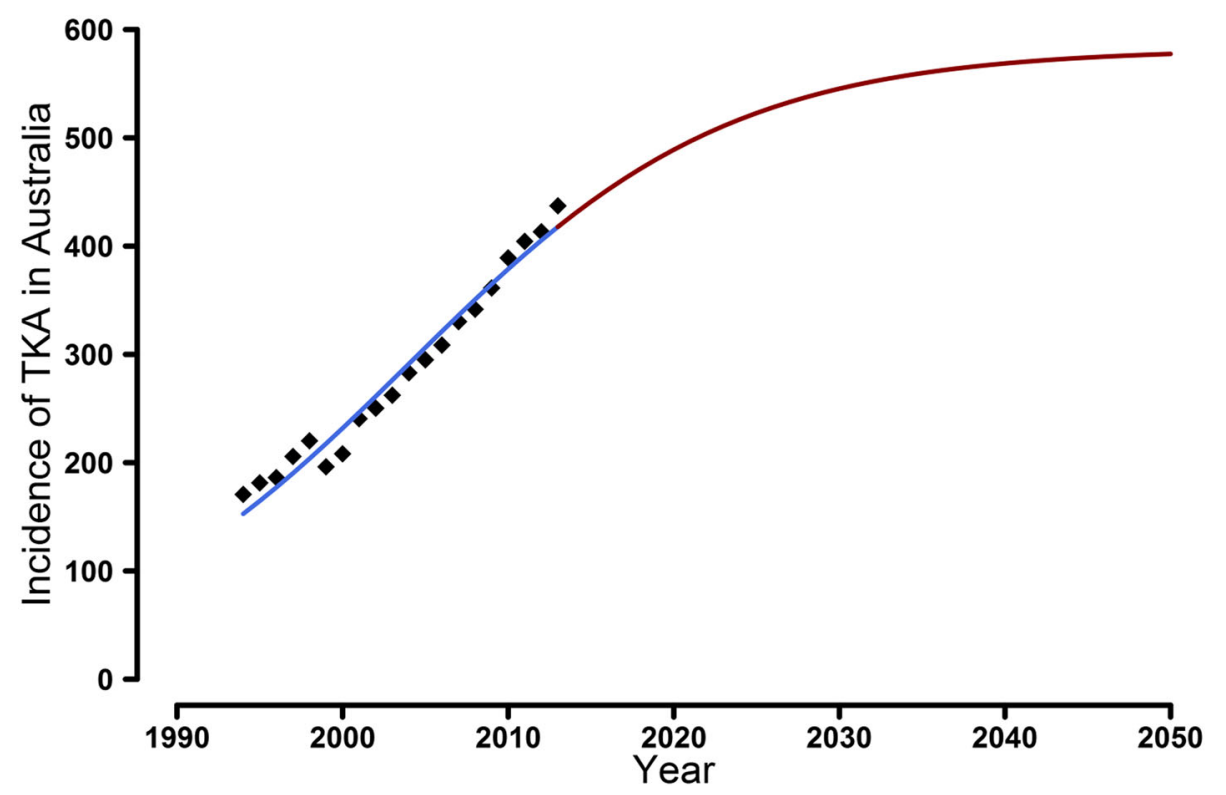

the direction of the effect on our estimations. Because projections also are limited by the period they cover, which means that longer-term projections are more unreliable, we limited our projections to 2046. Another limitation of our study is lack of evaluation of age group-specific projections, which could provide insight into specific subgroups of the population where the largest changes are observed. We also used administrative procedure codes to identify the TKAs and THAs evaluated in this study, which could have miscoding, errors, and other information bias owing to the nature of these data, however, we have no reason to believe this bias to be differential (that is, that it would vary from year to year) and so we do not believe it affects our overall findings.

The incidence of joint arthroplasties varies substantially around the world, with Australia being the country with the 7 th highest IR (178) of TKAs per 100,000 and 15th highest IR (171) of THAs per 100,000 [23, 24]. The five countries with the highest IR of TKAs per 100,000 population are the United States, Austria, Germany, Switzerland, and Finland, while the five with the highest IR of THAs are Switzerland, Germany, Austria, Norway, and Belgium [23, 24]. Similarly, the projected volume of joint arthroplasties, which worldwide is consistently expected to increase [13-15, 17, 18], varies widely. The magnitude of increase varies even within countries [9, 25]. One of the highest projected increases was reported for the United States, with expectations that a $673 \%$ increase in primary TKAs and $174 \%$ increase in THAs would be observed between 2005 and 2030 [12]. This is in contrast to the $25 \%$ projected increase in THAs and $49 \%$ projected increase in TKAs reported for the Swedish population between 2013 and $2030[20,21]$ and the $32 \%$ expected increase in THAs and
$40 \%$ expected increase in TKAs for the United Kingdom between 2015 and 2035 [9]. The differences in the magnitudes of these projections are most likely attributable to the studies' different modeling techniques and assumptions regarding population changes, both of which influence the projection figures. Some studies projecting orthopaedic procedures used Poisson regression modeling techniques and assumed an exponential future increase in the incidence of procedures [10, 12, 25]. This overestimates projections as it allows for an ever-increasing incidence of procedures. Conversely, a much more- conservative model, using a static IR to calculate future estimates has been used [9] and produces very conservative estimates. We used a logistic regression model, and consistent with Swedish research [20, 21], included the maximum incidence of procedures in the calculation of future projections yielding conservative projections but not assuming a static rate.

The large expected increase in the volume of joint arthroplasties in Australia is most likely attributable to the substantial projected increase in the population. The population of Australia is expected to increase by $41 \%$ between 2013 and 2036 (from 23.1 to 34.4 million) [3], which is substantially higher than the $13 \%$ expected for the United Sates [8], 10\% for the United Kingdom [22], or $11 \%$ for Sweden during a comparable period (2013-2030) [20]. In addition to the expected increase in population, the projected increase in the numbers of procedures could be attributed to factors which have been postulated by others $[16,17,27]$, including the changes in patient characteristics, expansion of surgical indications, willingness to undergo surgery, and less concern regarding complications from these procedures, which have much success and increasing survivability. 
Our estimates that the incidence of TKAs is expected to increase less than the incidence of THAs are contrary to estimates in other studies [9, 20, 21, 25], which reported the largest expected growth to be in the incidence or volume of TKAs. This difference is likely attributable to the already high IR of TKAs in the Australian population compared with other countries and our assumption that a maximum IR exists. In another words, because the incidence of TKAs is already high, it is likely that its growth is slowing as it approaches its asymptote, which is its expected maximum IR. This can be observed as the IR stops increasing and remains almost constant in later years (Fig. 2). This observation makes our findings especially relevant to other countries where a high IR and volume of TKAs already exist, like the United States and Germany [24]. This is not yet the case for the THA projections (Fig. 1), which will not reach its IR asymptote during the studied time. This observation also could be attributable to the limitations of our data, including the short time analyzed which translates to insecurities in the projected estimates (ie, wide confidence intervals).

Our projections of an increase in volume of joint arthroplasties in Australia during the next 30 years are informative clinically and financially for future planning for the Australian healthcare system. Furthermore, our findings confirm that a global trend in the increase of joint arthroplasties is projected, even when using a more-conservative projection approach, in a country with an already high incidence of arthroplasties. Appropriate workforce planning, resource allocation, and budget planning will be required so that demand can be met.

\section{References}

1. Ackerman IN, Bohensky MA, de Steiger R, Brand CA, Eskelinen A, Fenstad AM, Furnes O, Garellick G, Graves SE, Haapakoski J, Havelin LI, Makela K, Mehnert F, Pedersen AB, Robertsson O. Substantial rise in the lifetime risk of primary total knee replacement surgery for osteoarthritis from 2003 to 2013: an international, population-level analysis. Osteoarthritis Cartilage. 2017;25:455-461.

2. Ackerman IN, Bohensky MA, de Steiger R, Brand CA, Eskelinen A, Fenstad AM, Furnes O, Graves SE, Haapakoski J, Makela K, Mehnert F, Nemes S, Overgaard S, Pedersen AB, Garellick G. Lifetime risk of primary total hip replacement surgery for osteoarthritis from 2003-2013: a multi-national analysis using national registry data. Arthritis Care Res (Hoboken). 2017 Feb 2. [Epub ahead of print]

3. Australian Bureau of Statistics. Population Projections, Australia, 2012 (base) to 2016. Available at: http://www.abs.gov.au/ Ausstats/abs@.nsf/mf/3222.0. Accessed June 23, 2016.

4. Australian Government Department of Human Services. Medicare services. Available at: http://www.humanservices.gov.au/customer/ subjects/medicare-services. Accessed October 30, 2015.

5. Australian Orthopaedic Association National Joint Replacement Registry. Annual reports, 2014. Available at: https://aoanjrr.
sahmri.com/documents/10180/172286/Annual\%20Report\%202014. Accessed March 31, 2017.

6. Australian Orthopaedic Association National Joint Replacement Registry. Annual report, 2015. Analysis of State \& Territory Health Data All Arthroplasty Supplementary Report. Available at: https://aoanjrr.sahmri.com/documents/10180/217647/Analysis\% 20of\%20\%20State\%20\%26\%20Territory\%20Health\%20Data\%20 All\%20Arthroplasty. Accessed April 11, 2016.

7. Bini SA, Sidney S, Sorel M. Slowing demand for total joint arthroplasty in a population of 3.2 million. J Arthroplasty. 2011;26 (6 suppl): 124-128.

8. Colby SL, Ortman JM. Projections of the Size and Composition of the U.S. Population: 2014 to 2060: Population Estimates and Projections. Current Population Reports. U.S. Department of Commerce, Economics and Statistics Administration, U.S. Census Bureau. Available at: https://www.census.gov/content/dam/ Census/library/publications/2015/demo/p25-1143.pdf. Accessed April 27, 2017.

9. Culliford D, Maskell J, Judge A, Cooper C, Prieto-Alhambra D, Arden NK; COASt Study Group. Future projections of total hip and knee arthroplasty in the UK: results from the UK Clinical Practice Research Datalink. Osteoarthritis Cartilage. 2015;23:594-600.

10. Hooper G, Lee AJ, Rothwell A, Frampton C. Current trends and projections in the utilisation rates of hip and knee replacement in New Zealand from 2001 to 2026. N Z Med J. 2014;127:82-93.

11. Khatod M, Inacio M, Paxton EW, Bini SA, Namba RS, Burchette RJ, Fithian DC. Knee replacement: epidemiology, outcomes, and trends in Southern California: 17,080 replacements from 1995 through 2004. Acta Orthop. 2008;79:812-819.

12. Kurtz S, Ong K, Lau E, Mowat F, Halpern M. Projections of primary and revision hip and knee arthroplasty in the United States from 2005 to 2030. J Bone Joint Surg Am. 2007;89:780-785.

13. Kurtz SM, Ong KL, Lau E, Bozic KJ. Impact of the economic downturn on total joint replacement demand in the United States: updated projections to 2021. J Bone Joint Surg Am. 2014;96:6246330.

14. Kurtz SM, Ong KL, Lau E, Widmer M, Maravic M, GomezBarrena E, de Pina Mde F, Manno V, Torre M, Walter WL, de Steiger R, Geesink RG, Peltola M, Roder C. International survey of primary and revision total knee replacement. Int Orthop. 2011;35:1783-1789.

15. Leskinen J, Eskelinen A, Huhtala H, Paavolainen P, Remes V. The incidence of knee arthroplasty for primary osteoarthritis grows rapidly among baby boomers: a population-based study in Finland. Arthritis Rheum. 2012;64:423-428.

16. Losina E, Thornhill TS, Rome BN, Wright J, Katz JN. The dramatic increase in total knee replacement utilization rates in the United States cannot be fully explained by growth in population size and the obesity epidemic. J Bone Joint Surg Am. 2012;94:201-207.

17. March LM, Bagga H. Epidemiology of osteoarthritis in Australia. Med J Aust. 2004;180(5 suppl): S6-10.

18. McGuirk P, Argent N. Population growth and change: implications for Australia's cities and regions. Geographical Research. 2011;49:317-335. Available at: http://ro.uow.edu.au/cgi/viewcont ent.cgi? article $=3246 \&$ context $=$ sspapers. Accessed November 28, 2016.

19. Mekid S, Vaja D. Propagation of uncertainty: expressions of second and third order uncertainty with third and fourth moments. Measurement. 2008;41:600-609.

20. Nemes S, Gordon M, Rogmark C, Rolfson O. Projections of total hip replacement in Sweden from 2013 to 2030. Acta Orthop. 2014;85:238-243.

21. Nemes S, Rolfson O, W-Dahl A, Garellick G, Sundberg M, Karrholm J, Robertsson O. Historical view and future demand for knee arthroplasty in Sweden. Acta Orthop. 2015:86:426-443. 
22. Office for National Statistics. National Population Projections: 2014-based Statistical Bulletin. Available at: https://www.ons. gov.uk/peoplepopulationandcommunity/populationandmigration/ populationprojections/bulletins/nationalpopulationprojections/201510-29. Accessed March 31, 2017.

23. Pabinger C, Geissler A. Utilization rates of hip arthroplasty in OECD countries. Osteoarthritis Cartilage. 2014;22:734-741.

24. Pabinger $\mathrm{C}$, Lothaller $\mathrm{H}$, Geissler A. Utilization rates of kneearthroplasty in OECD countries. Osteoarthritis Cartilage. 2015;23:1664-1673.

25. Patel A, Pavlou G, Mujica-Mota RE, Toms AD. The epidemiology of revision total knee and hip arthroplasty in England and
Wales: a comparative analysis with projections for the United States. A study using the National Joint Registry dataset. Bone Joint J. 2015;97:1076-1081.

26. Singh JA. Epidemiology of knee and hip arthroplasty: a systematic review. Open Orthop J. 2011;5:80-85.

27. Walls HL, Magliano DJ, Stevenson CE, Backholer K, Mannan HR, Shaw JE, Peeters A. Projected progression of the prevalence of obesity in Australia. Obesity (Silver Spring). 2012;20:872-878.

28. Wells VM, Hearn TC, McCaul KA, Anderton SM, Wigg AE, Graves SE. Changing incidence of primary total hip arthroplasty and total knee arthroplasty for primary osteoarthritis. J Arthroplasty. 2002;17:267-273. 